\title{
Serge Doubrovsky, Parcours critiques II (1959-1991)
}

\section{Fatima Pilone}

\section{(2) OpenEdition}

\section{Journals}

\section{Edizione digitale}

URL: http://journals.openedition.org/studifrancesi/9717

DOI: 10.4000/studifrancesi.9717

ISSN: 2427-5856

\section{Editore}

Rosenberg \& Sellier

\section{Edizione cartacea}

Data di pubblicazione: 1 décembre 2007

Paginazione: $710-711$

ISSN: 0039-2944

Notizia bibliografica digitale

Fatima Pilone, «Serge Doubrovsky, Parcours critiques I/ (1959-1991)», Studi Francesi [Online], 153 (LI |

III) | 2007, online dal 30 novembre 2015, consultato il 10 janvier 2021. URL: http://

journals.openedition.org/studifrancesi/9717 ; DOI: https://doi.org/10.4000/studifrancesi.9717

Questo documento è stato generato automaticamente il 10 janvier 2021.

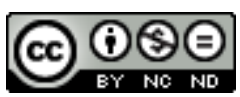

Studi Francesi è distribuita con Licenza Creative Commons Attribuzione - Non commerciale - Non opere derivate 4.0 Internazionale. 


\title{
Serge Doubrovsky, Parcours critiques II (1959-1991)
}

\author{
Fatima Pilone
}

\section{NOTIZIA}

SERGE DOUBROVSKY, Parcours critiques II (1959-1991), texte établi par Isabelle GRELL, Grenoble, Ellug Université Stendhal, «Archives Critiques», 2006, pp. 133.

1 Il testo è inserito all'interno della collana «Archives Critiques» diretta da Lise Dumasy e Jean-François Louette, collana che ha lo scopo di arricchire il dibattito critico, mettendo a disposizione testi poco conosciuti o difficilmente reperibili.

2 Serge Doubrovsky, professore all'Università di New York, è molto citato soprattutto per aver introdotto nella lingua letteraria il termine autofiction. Ma è anche notoriamente autore di saggi importanti (citiamo solo, a titolo di esempio, Corneille et la dialectique du héros e La place de la madeleine, Écritures et fantasme chez Proust), di scritti teorici come Pourquoi la nouvelle critique. Critique et objectivité, di opere costruite attraverso l'esperienza della psicanalisi, guardando ai testi da un punto di vista nuovo rispetto all'approccio critico classico, con lo scopo di scovare l'atto della scrittura nelle e tra le righe: il compito del critico diventa, per Doubrovsky, quello di svelare l'esperienza della parole che si trasforma in écriture.

Dopo aver selezionato in modo scrupoloso gli autori da trattare, l'intento di Doubrovsky è superare il mero testo e le costrizioni della lettura e giungere quindi alla fonte vera della scrittura, alle cause che scatenano l'attività creativa, per svelare la struttura che sta alla base degli imponenti edifici della letteratura. Per far questo, l'autore fonde nella scrittura le tecniche del critico con quelle del romanziere.

Gli articoli raccolti, scelti tra i molti pubblicati ne «La Nouvelle Revue Française», in «Poétique» e nella «Revue des Sciences humaines», sono proposti essenzialmente con una divisione in due blocchi: la sezione del xx secolo (Le rire d'Eugène Ionesco, Camus et l'Amérique, Claude Vigée, ou le mot de vie, Roland Barthes, une écriture tragique e Sartre: 
autobiographie/autofiction) e la sezione consacrata al XVII secolo ("La Princesse de Clèves". Une interprétation existentielle, Arnolphe ou la chute du héros e Pierre Corneille, cet étrange monstre). La curatrice ha voluto mantenere, anche nella proposta grafica dell'impaginato, l'impostazione privilegiata dallo stesso Doubrovsky.

5 Il lettore troverà inoltre un'intervista concessa da Doubrovsky alla curatrice della raccolta, Isabelle Grell, nel 2005, dove egli parla della propria vita, divisa in due tra critica e scrittura. È l'occasione per Doubrovsky di diffondersi sulla sua passione per Sartre, sui suoi incontri con Barthes e Robbe-Grillet, definiti autori nella cui scrittura c'è qualcosa che fa «vibrer une corde chez lui».

Conclude il volume l'indice alfabetico degli autori citati. 